\title{
Evaluating the lethal and pre-lethal effects of a range of fungi against adult Anopheles stephensi mosquitoes
}

\author{
Simon Blanford ${ }^{1,2^{*}}$, Nina E Jenkins ${ }^{2}$, Andrew F Read ${ }^{1,2,3}$ and Matthew B Thomas ${ }^{2}$
}

\begin{abstract}
Background: Insecticide resistance is seriously undermining efforts to eliminate malaria. In response, research on alternatives to the use of chemical insecticides against adult mosquito vectors has been increasing. Fungal entomopathogens formulated as biopesticides have received much attention and have shown considerable potential. This research has necessarily focused on relatively few fungal isolates in order to 'prove concept'. Further, most attention has been paid to examining fungal virulence (lethality) and not the other properties of fungal infection that might also contribute to reducing transmission potential. Here, a range of fungal isolates were screened to examine variation in virulence and how this relates to additional pre-lethal reductions in feeding propensity.

Methods: The Asian malaria vector, Anopheles stephensi was exposed to 17 different isolates of entomopathogenic fungi belonging to species of Beauveria bassiana, Metarhizium anisopliae, Metarhizium acridum and Isaria farinosus. Each isolate was applied to a test substrate at a standard dose rate of $1 \times 10^{9}$ spores $\mathrm{ml}^{-1}$ and the mosquitoes exposed for six hours. Subsequently the insects were removed to mesh cages where survival was monitored over the next 14 days. During this incubation period the mosquitoes' propensity to feed was assayed for each isolate by offering a feeding stimulant at the side of the cage and recording the number probing.

Results and conclusions: Fungal isolates showed a range of virulence to A. stephensi with some causing $>80 \%$ mortality within 7 days, while others caused little increase in mortality relative to controls over the study period. Similarly, some isolates had a large impact on feeding propensity, causing $>50 \%$ pre-lethal reductions in feeding rate, whereas other isolates had very little impact. There was clear correlation between fungal virulence and feeding reduction with virulence explaining nearly $70 \%$ of the variation in feeding reduction. However, there were some isolates where either feeding decline was not associated with high virulence, or virulence did not automatically prompt large declines in feeding. These results are discussed in the context of choosing optimum fungal isolates for biopesticide development.
\end{abstract}

\section{Background}

A number of recent reports suggest that the continued efficacy of malaria and mosquito vector control tools is threatened by drug and insecticide resistance [1-6]. The rise in pyrethroid resistance [5], the primary class of insecticide used in public health, is eroding efforts to control vectors with insecticide-treated nets (ITNs) and

\footnotetext{
*Correspondence: stb13@psu.edu

${ }^{1}$ Center for Infectious Disease Dynamics, Department of Biology, Penn State

University Mueller Laboratory, University Park, PA 16802, USA

${ }^{2}$ Center for Infectious Disease Dynamics, Department of Entomology, Penn

State University Merkle Lab, University Park, PA 16802, USA

Full list of author information is available at the end of the article
}

insecticide residual sprays (IRS) [7-11]. In the face of this resistance evolution, recent years have seen an increased interest in alternative vector control methods. One such approach is the use of fungal entomopathogens as novel active ingredients for use in biopesticides [12,13].

Fungi can be formulated and applied like chemical insecticides [14] and could be delivered through conventional approaches, such as IRS, or novel strategies such as resting targets $[13,15]$, eave curtains [16] or odour baited traps [17]. Fungal pathogens have been shown to be effective against a range of vectors [18-22] including insecticide susceptible, resistant and multi-resistant mosquitoes [18]

\section{Biomed Central}


and to impact on the transmission potential of these vectors through effects which include reductions in feeding $[12,18,21,23]$, fecundity $[18,23]$, reduced flight capability [18], host location [24] and elevated metabolic rates [18]. In addition, recent work has shown that fungal shelf-life and post application persistence (important criteria for the active ingredient of any IRS product) on some surfaces can be comparable to chemical insecticides [Authors' submitted manuscript].

These advances are encouraging but have not been without criticism [25], in part because fungi induce relatively slow mortality (often 7-14 days to reach $>90 \%$ mortality) and this does not fit with the fast acting chemical insecticide target product profiles prescribed by the World Health Organization Pesticide Evaluation Scheme (WHOPES) [26]. However, rapid mortality is not always required for delivering effective malaria control [12,14,27-29] and there are potential benefits of a slow speed of kill for alleviating resistance evolution $[29,30]$. Furthermore, as indicated above, fungal infection can affect mosquito life history in multiple ways and virulence (speed of kill) is only one measure of pathogen impact.

The nature and extent of the lethal and pre-lethal effects of a fungal biopesticide will depend on the fungal isolate, the dose applied, the efficiency of dose transfer (affected by formulation, substrate and exposure time) and the temperature during fungal incubation in the vector [12,31-33]. To date around forty experimental studies have been reported examining some aspect of fungal infection on adult mosquito vectors [12,13,15-19,21-24,31-57]. These studies include multiple fungal isolates from eight genera and twenty-one species. In spite of this diversity, the majority of recent studies consider only a handful of fungal isolates and have tended to focus on virulence alone. This study evaluated the virulence of 17 isolates of the entomopathogenic fungi Beauveria bassiana, Metarhizium anisopliae, M. acridum and Isaria farinosus against the Asian vector mosquito Anopheles stephensi. In addition these isolates ability to affect feeding propensity and the relationship between virulence and alterations in feeding behaviour following fungal infection was assessed. These results are discussed in the context of making rational choices for malaria control products.

\section{Methods}

\section{Fungal preparation and formulation}

Fungal isolates (Table 1) were selected from a collection of isolates known to infect a diversity of insect taxa (including Diptera) and hence are reasonable candidates to infect Anopheles mosquitoes.

Conidia were harvested from slopes or plates to make a spore suspension of approximately $1 \times 10^{6}$ conidia $\mathrm{ml}^{-1}$ in sterile $0.05 \% \mathrm{w} / \mathrm{v}$ Tween 80 (Sigma) in distilled water. One $\mathrm{ml}$ of this suspension was then used to inoculate $75 \mathrm{ml}$ sterile liquid medium culture medium (4\% d-Glucose, $2 \%$ yeast extract [Oxoid, UK] in tap water), in $250 \mathrm{ml}$ Erlenmyer flasks. Flasks were incubated on a rotary shaker (160 rpm) at $24^{\circ} \mathrm{C}$ for 3 days.

Barley flakes (Bobs Red Mill, Milwaukie, Oregon, USA) were weighed into mushroom spawn bags (Unicorn, Garland, Texas, USA), $1 \mathrm{~kg}$ per bag and $600 \mathrm{ml}$ tap water was added and the contents mixed by hand to ensure even absorption of the water. The spawn bags were then placed inside autoclave bags for protection and autoclaved for $30 \mathrm{~min}$ at $121^{\circ} \mathrm{C}$. Once cool, the bags were inoculated under aseptic conditions with $75 \mathrm{ml}$ of the 4-day old liquid medium plus $75 \mathrm{ml}$ of sterile water to achieve a final moisture content of approximately $48 \%$. The inoculated bags were carefully massaged to ensure even distribution of the inoculum. The bags were then sealed and incubated on shelves for 10 days at $24^{\circ} \mathrm{C}$. Following incubation, the bags were opened in a reverse flow cabinet (Labconco, USA) and the contents transferred to brown paper bags for drying. The paper bags were placed in a dehumidified room for 4 days $\left(24-30^{\circ} \mathrm{C}\right)$, until the sporulated substrate reached $<20 \%$ moisture content. The conidia were then harvested from the barley flakes using a Mycoharvester (Acis Manufacturing, Devon, UK). The harvested conidia were placed in glass dishes and further dried in a desiccator over dry silica gel at $24^{\circ} \mathrm{C}$. Once the conidia powder reached $5 \%$ moisture content, a small sample was taken for quality analysis and the remaining powder was sealed in foil laminated sachets with a small sachet of silica gel and stored at $5^{\circ} \mathrm{C}$ until use.

To test the viability of conidia in the formulation prior to spraying, $0.5 \mathrm{ml}$ of the 'stock' was taken and diluted in pure Isopar $\mathrm{M}$ to a concentration of approximately $1 \times 10^{7}$ conidia $\mathrm{ml}^{-1}$. One drop of this suspension was transferred onto SDA in $6 \mathrm{~cm}$ diameter Petri plates using a microspatula and spread evenly over the surface of the agar. Three plates were prepared for each isolate formulation and incubated at $25^{\circ} \mathrm{C}$ for $20 \mathrm{hr}$. After incubation, the conidia on the agar surface were examined under a compound microscope (at 500× magnification). Conidia were counted as germinated if a germ was visibly protruding from the conidium and all conidia in each field of view were assessed. A total of at least 300 conidia were counted per plate and viability was calculated as a percentage of the total.

\section{Mosquito rearing}

Anopheles stephensi were reared under standard insectary conditions at $27^{\circ} \mathrm{C}, 80 \%$ humidity and $12 \mathrm{~L}: 12 \mathrm{D}$ photo-period. The colony has been at Penn State for four years and was obtained from National Institute of Health where it has been in culture for at least a 
Table 1 Species, country of origin and the original host the fungal isolate was collected from (where known) for each of the isolates used in this study

\begin{tabular}{llll}
\hline Fungal isolate & Species & Host origin & Country of origin \\
\hline Bb01 & Beauveria bassiana & Coleoptera: Chysomelidae & USA \\
Bb02 & Beauveria bassiana & Musca domestica (Diptera: Muscidae) & USA \\
Bb03 & Beauveria bassiana & Delia radicans (Diptera: Delphacidae) & Canada \\
Bb04 & Beauveria bassiana & Nilparvata lugens (Hemiptera: Delphacidae) & Solomon Islands \\
Bb05 & Beauveria bassiana & Musca domestica (Diptera: Muscidae) & USA \\
Bb06 & Beauveria bassiana & Musca autumnalis (Diptera: Calliphoridae) & France \\
Bb07 & Beauveria bassiana & Soil sample & Australia \\
Ma01 & Metarhizium acridum & Ornithacris cavroisi (Orthorptera: Acrididae) & Niger \\
Ma02 & Metarhizium robertsii & Curculio caryae (Coleoptera: Curculionidae) & USA \\
Ma03 & Metarhizium robertsii & Curculio caryae (Coleoptera: Curculionidae) & USA \\
Ma04 & Metarhizium robertsii & Curculio caryae (Coleoptera: Curculionidae) & USA \\
Ma05 & Metarhizium anisopliae & Busseola fusca (Lepidoptera: Noctuidae) & Kenya \\
Ma06 & Metarhizium anisopliae & Aedes triseriatus (Diptera: Culicidae) & USA \\
Ma07 & Metarhizium anisopliae & Inopus rubriceps (Diptera: Stratiomyidae) & Australia \\
Ma08 & Metarhizium brunneum & Carpocapsa pomonella (Lepidoptera: Olethreutidae) & Austria \\
Ma09 & Metarhizium robertsii & Conoderus sp. (Coleoptera: Elateridae) & USA \\
If01 & Isaria farinosus & Diptera: Tachinidae & Poland
\end{tabular}

further ten years. Eggs were placed in plastic trays $(25 \mathrm{~cm} \times$ $25 \mathrm{~cm} \times 7 \mathrm{~cm}$ ) filled with 1.51 of distilled water. To reduce variation in adult size at emergence, larvae were reared at a fixed density of 400 per tray. Larvae were fed Liquifry for five days and then Tetrafin fish flakes. From approximately two weeks after egg hatch, pupae were collected daily and placed in emergence cages. The adults that emerged were fed ad libitum on a $10 \%$ glucose solution. All experiments used three-to-five day old adult female mosquitoes.

\section{Virulence assays}

Application of fungal suspension to the test substrates (cardboard pots) was carried out following a wellestablished methodology $[12,39,40]$. In brief the fungal conidia were formulated in a mix of mineral oils $(80 \%$ Isopar M: 20\% Ondina 22) similar to that described previously [12] and the concentration adjusted to give $1 \times 10^{9}$ conidia $\mathrm{ml}^{-1}$. Spray applications employed a handheld artist's air-brush, which produced an aerosol of the formulation from a $25 \mathrm{ml}$ glass reservoir attached to the spray nozzle. Each waxed cardboard challenge pot was opened and attached flat to the centre of the $1 \mathrm{~m}^{2}$ vertical spray zone within a laminar-flow hood. $20 \mathrm{ml}$ of suspension was sprayed evenly from a distance of $25 \mathrm{~cm}$ across the entire spray zone providing a theoretical dose (see 39 ) of $2 \times 10^{6}$ conidia $\mathrm{cm}^{-}{ }^{2}$. This dose is not a maximal operational dose or the large experimental dose and application rates that have shown very rapid mortality previously [18], but should represent a discriminating dose sufficient to distinguish between isolates on the basis of intrinsic variation in virulence. Pots were reassembled and left to dry for 24 h. 30 adult female mosquitoes were then transferred to each pot and left in place for $6 \mathrm{~h}$ before being removed to standard mosquito cages $(30 \times 30 \times 30 \mathrm{~cm})$ where they were maintained on an ad libitum supply of glucose water at $26( \pm 1)^{\circ} \mathrm{C}$ and 85 $( \pm 10) \%$ RH. Mortality was recorded daily for 14 days after exposure. Each isolate was applied to 4 replicate pots and paired to equivalent control pots treated with blank formulation only.

\section{Feeding propensity assays}

Feeding propensity was assessed using an established methodology [18]. Mosquitoes were offered a feeding stimulus comprising a $250 \mathrm{ml}$ flask filled with hot tap water $\left(\sim 35-40^{\circ} \mathrm{C}\right)$ and covered socks worn recently by with one of the investigators (SB). This stimulus provides both a heat and odor cue and is a routine technique for sorting female from male An. stephensi for experimental purposes in the laboratory. The stimulus was placed adjacent to a mosquito cage and the proportion of mosquitoes recruiting to the cage wall and observed actively probing through the mesh over a 5-minute period, recorded. This assay was repeated daily for each replicate cage for each isolate and its respective controls.

\section{Statistical analysis}

For all treatments median survival times were analysed using a Kaplan-Meier survival analysis in SPSS for Mac 
Table 2 Effects of a range of fungal isolates on survival of adult Anopheles stephensi

\begin{tabular}{|c|c|c|c|c|}
\hline $\begin{array}{l}\text { Fungal isolate } \\
\text { Number }\end{array}$ & $\begin{array}{l}\text { Median lethal time } \\
(95 \% \text { C.I.) days }\end{array}$ & $\begin{array}{l}\text { Log rank statistic (Significance } \\
\text { compared to controls) }\end{array}$ & $\begin{array}{l}\text { Time to } 80 \% \text { mortality } \\
( \pm 1 \text { SEM) days }\end{array}$ & $\begin{array}{l}\text { Hazard ratio } \\
(95 \% \text { C.I.) }\end{array}$ \\
\hline \multicolumn{5}{|c|}{ Beauveria spp. } \\
\hline Bb01 & $6.0(5.81-6.19)$ & $247.7(P<0.001)$ & $7.3( \pm 0.25)$ & $3.93(3.26-4.72)$ \\
\hline $\mathrm{Bb} 02$ & $7.0(6.64-7.36)$ & $74.4(P<0.001)$ & $6.0( \pm 0.00)$ & $2.54(2.01-3.21)$ \\
\hline $\mathrm{Bb} 03$ & $5.0(4.80-5.20)$ & $249.6(P<0.001)$ & $9.3( \pm 0.25)$ & $11.0(8.3-14.6)$ \\
\hline $\mathrm{Bb} 04$ & $9.0(8.53-9.47)$ & $17.5(P<0.001)$ & $11.3( \pm 0.48)$ & $1.55(1.22-1.97)$ \\
\hline Bb05 & $6.0(5.66-6.34)$ & $170.1(P<0.001)$ & $8.0( \pm 0.00)$ & $8.53(6.21-11.7)$ \\
\hline Bb06 & $10.0(9.04-10.96)$ & $45.9(P<0.001)$ & $13.3( \pm 0.25)$ & $2.65(1.92-3.64)$ \\
\hline Bb07 & $8.0(7.54-8.46)$ & $122.9(P<0.001)$ & $10.3( \pm 0.96)$ & $4.83(3.52-6.62)$ \\
\hline \multicolumn{5}{|c|}{ Metarhizium spp. } \\
\hline Ma01 & $11.0(10.21-11.79)$ & $0.37(P=0.54)$ & Not achieved & $0.94(0.77-1.45)$ \\
\hline $\mathrm{Ma02}$ & $13.0(11.72-14.28)$ & $43.6(P<0.001)$ & Not achieved & $2.24(1.73-2.90)$ \\
\hline $\mathrm{Ma03}$ & $12.0(10.47-13.53)$ & $47.5(P<0.001)$ & Not achieved & $2.38(1.83-3.11)$ \\
\hline Ma04 & $11.0(9.80-12.20)$ & $59.0(P<0.001)$ & Not achieved & $2.16(1.99-3.42)$ \\
\hline Ma05 & $6.0(5.75-6.25)$ & $357.9(P<0.001)$ & $11.3( \pm 1.03)$ & $7.85(6.10-10.1)$ \\
\hline Ma06 & $6.0(5.56-6.44)$ & $369.1(P<0.001)$ & $10.0( \pm 0.41)$ & $8.48(6.60-10.9)$ \\
\hline Ma07 & $6.0(5.71-6.29)$ & $339.0(P<0.001)$ & $8.0( \pm 0.41)$ & $5.70(4.69-6.93)$ \\
\hline Ma08 & $6.0(5.75-6.25)$ & $288.3(P<0.001)$ & $8.5( \pm 0.65)$ & $4.89(3.98-6.01)$ \\
\hline Ma09 & $8.0(7.17-8.83)$ & $73.2(P<0.001)$ & $13.0( \pm 0.00)$ & $3.41(2.52-4.60)$ \\
\hline \multicolumn{5}{|c|}{ Isaria farinosus } \\
\hline If01 & Not calculated & $5.9(P=0.015)$ & Not achieved & 1.45 (1.07-1.97) \\
\hline
\end{tabular}

Included are the median lethal time from Kaplain-Meier analysis and its significance relative to paired controls; time to $80 \%$ mortality $( \pm 1$ standard error around the mean mortality across the replicate cages); and the hazard ratio estimated from a Cox regression which gives a measure of mortality risk relative to the controls.

(v.19) with significant differences between doses and/or treatments estimated using a Log Rank Test. To examine feeding behaviour, repeated measures ANOVAs were performed on the mean proportion of mosquitoes attempting to feed each day from day 1 after exposure until mortality had reached $80 \%$, or if this level was not

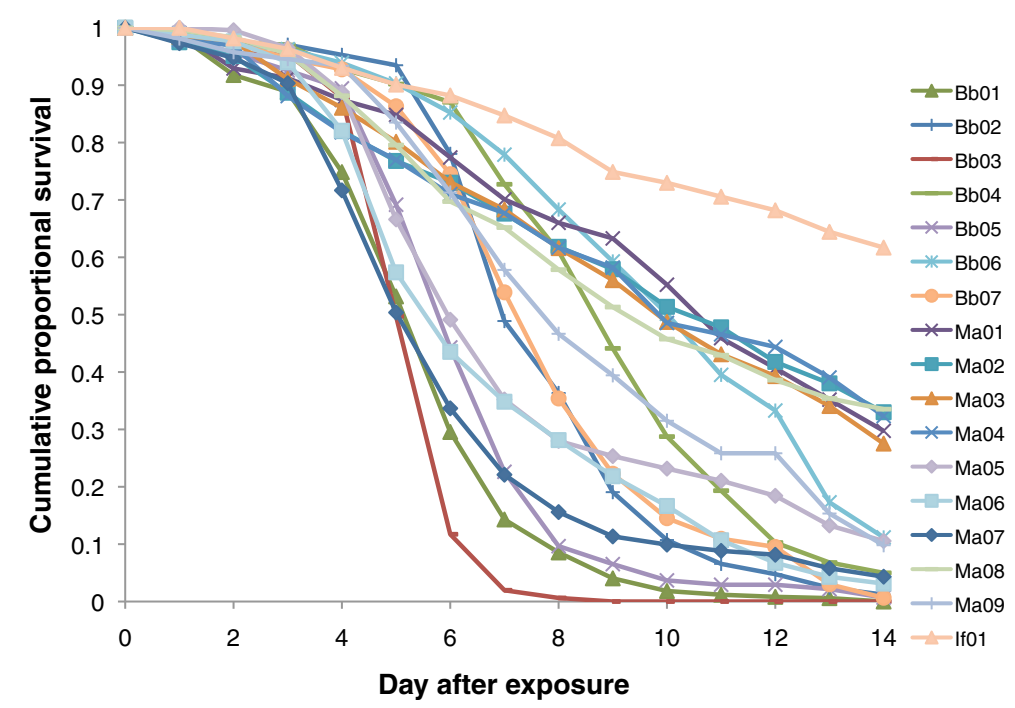

Figure 1 Cumulative proportional survival of Anopheles stephensi exposed to different isolates of entomopathogenic fungi. Mosquitoes were exposed to isolates of Beauveria bassiana, Metarhizium spp. and Isaria farinosus and their survival followed for fourteen days following exposure. For ease of comparison the figure omits the daily error bars and also excludes the control treatments paired to each of the 17 isolates. 
achieved, then by the end of day 14 . To determine the $\mathrm{LT}_{80}$ (the time to $80 \%$ mortality, which is the minimum mortality considered acceptable by WHOPES [42]) Weibull functions were fitted to the survival data:

$$
S=\exp \left[-(\mathrm{A} / \mathrm{G}) t^{\mathrm{G}}\right]
$$

where $\mathrm{S}$ is proportional survival, $\mathrm{A}$ and $\mathrm{G}$ are best-fit parameters and $t$ is time.

\section{Results}

\section{Survival}

All but one of the fungal isolates tested caused significantly increased mortality of adult $A$. stephensi relative to the paired controls (Table 2) but there was large variation between isolates (Figure 1). Several isolates caused high levels of mortality with the most virulent (B. bassiana - Bb03) exhibiting a median survival time of 5 days and an $\mathrm{LT}_{80}$ of 5.8 days. Other isolates were less virulent, with some failing to achieve $80 \%$ mortality with the 14 days. The one isolate that did not differ from its control was one of the M. anisopliae isolates (Ma01), but in this case the controls showed much higher mortality than normal, possibly obscuring a treatment effect. In absolute terms, the single isolate of $I$. farinosus was the least virulent. There were no consistent differences between $B$. bassiana and Metarhizium spp isolates when the hazard ratios were ranked (Figure 2A).
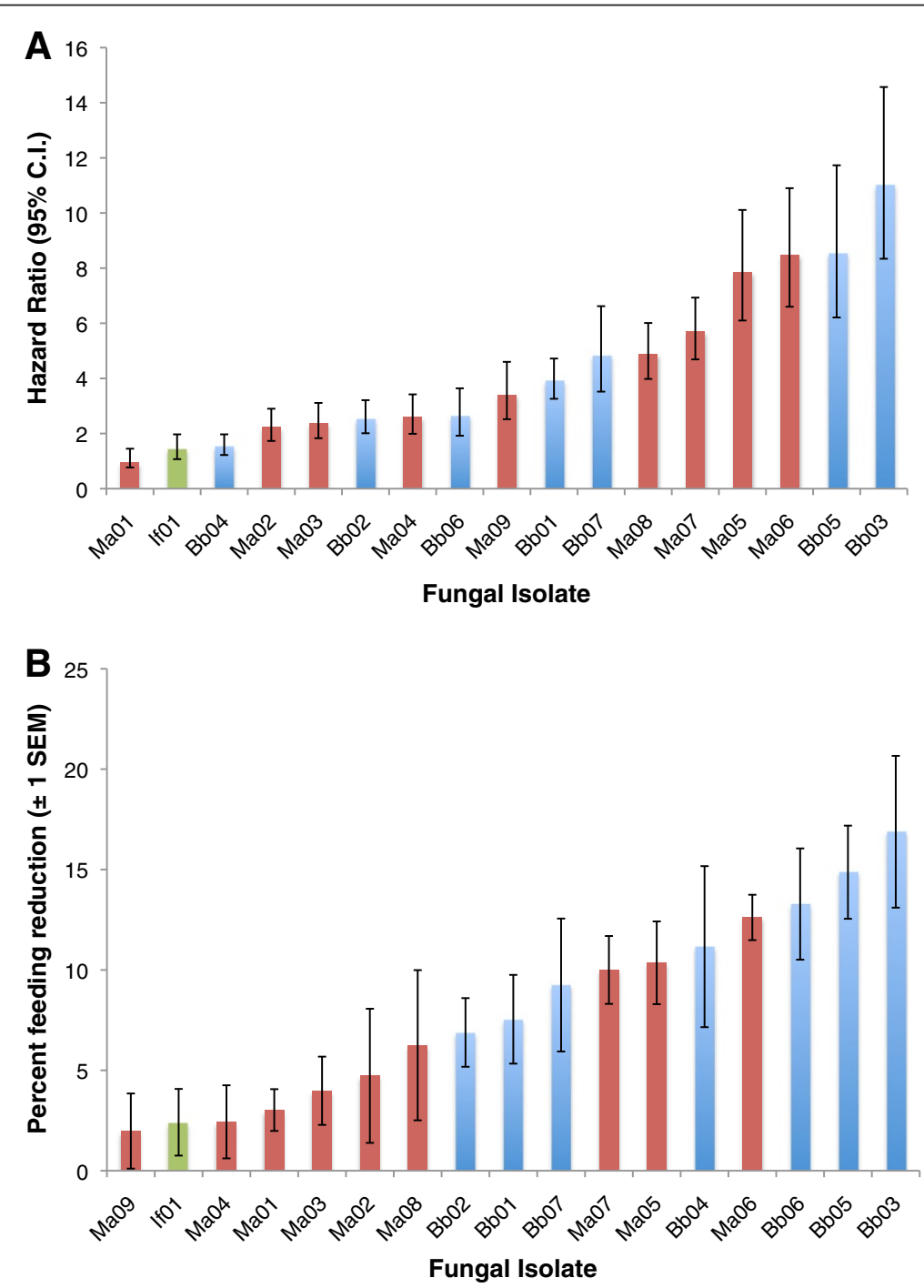

Figure 2 Rank order of A) fungal virulence and B) impact on feeding propensity for 17 entomopathogenic fungal isolates. Virulence is shown as the hazard ratio for each isolate estimated from a Cox regression. Impact on feeding propensity is based on the average reduction in feeding propensity until $80 \%$ of mosquitoes were dead, or until the end of the assay if mortality was less. Feeding propensity is corrected by subtracting the mean control feeding propensity over the same period. For each graph blue columns are B. bassiana isolates, red columns Metarhizium isolates and the green columns an Isaria farinosus isolate. 


\section{Feeding propensity}

Declines in feeding propensity were clearly apparent in 10 of the isolates tested (Table 3). All B. bassiana isolates except Bb06 caused a significant reduction in feeding propensity (Table 3 and Figure 2B). The maximum reduction in feeding relative to controls on any one day was between 40 and $50 \%$ for several isolates. The Metarhizium isolates were much more variable with only 4 significantly reducing feeding propensity (Table 3 and Figure 2B). The Isaria If01 isolate had no impact on feeding propensity. Ranking the extent of feeding decline by comparing the average difference in feeding propensity between fungal exposed and control mosquitoes across the duration of the study (a conservative measure relative to the maximum) showed that $B$. bassiana isolates had a greater impact on feeding behaviour than Metarhizium isolates (Figure 2B).

\section{Correlation between survival and feeding}

Regression analysis revealed a significant positive association between the proportion of mosquitoes not responding to the feeding stimulus and fungal virulence (measured as the hazard ratio) $\left(F_{1,14}=30.0, P<0.001 ; \mathrm{R}^{2}=0.68\right.$; Figure 3). A couple of B. bassiana isolates that showed only low-to-intermediate virulence (Bb04 and Bb06) had higher impacts on feeding than their mortality hazard ratios might predict. There was no real evidence for the reverse pattern of high virulent isolates having negligible impacts on feeding. The one possible exception was Metarhizium isolate Ma01, which had no survival impact but still a significant effect on feeding propensity. However, as discussed above, the survival data for this isolate are slightly difficult to interpret as the control group suffered higher than expected mortality.

Biting risk (the product of mortality and feeding propensity) at day 14 , which is approximately the time at which a mosquito could potentially transmit malaria if it acquired the parasite at its first blood feed, showed that all $B$. bassiana isolates had a large impact on transmission potential. For 5 out of the 7 isolates, biting risk was reduced to zero (and for one of these remaining isolates,

Table 3 Effects of a range of fungal isolates on the blood-feeding propensity of adult Anopheles stephensi

\begin{tabular}{|c|c|c|c|c|}
\hline Fungal isolate number & $\begin{array}{l}\text { F statistic } \\
\text { (Significance level) }^{a}\end{array}$ & $\begin{array}{l}\text { Overall percent feeding } \\
\text { decline }^{b}( \pm 1 \text { SEM) }\end{array}$ & $\begin{array}{l}\text { Maximum percent feeding } \\
\text { decline }( \pm 1 \text { SEM) }\end{array}$ & $\begin{array}{l}\text { Percent biting risk at day } \\
14^{\mathrm{c}} \text { (difference to controls) }\end{array}$ \\
\hline \multicolumn{5}{|c|}{ Beauveria spp. } \\
\hline Bb01 & $20.9(P=0.004)$ & $7.54( \pm 2.21)$ & $17.8( \pm 6.51)$ & $0(-)^{*}$ \\
\hline $\mathrm{Bb02}$ & $29.2(P=0.002)$ & $6.89( \pm 1.71)$ & $18.9( \pm 9.89)$ & $0.6(-11.5)$ \\
\hline $\mathrm{Bb03}$ & $294.3(P<0.001)$ & $16.9( \pm 3.78)$ & $48.8( \pm 18.7)$ & $0(-)^{*}$ \\
\hline Bb04 & $107.3(P<0.001)$ & $11.2( \pm 4.01)$ & $35.8( \pm 15.5)$ & $0(-)^{\S}$ \\
\hline Bb05 & $29.4(P=0.002)$ & $14.9( \pm 2.32)$ & $38.3( \pm 13.5)$ & $0(-)^{\S}$ \\
\hline $\mathrm{Bb06}$ & $0.26(P=0.63)$ & $13.3( \pm 2.77)$ & $19.3( \pm 6.50)$ & $10.7(-31.9)$ \\
\hline $\mathrm{Bb} 07$ & $6.26(P=0.046)$ & $9.25( \pm 3.31)$ & $42.8( \pm 23.7)$ & $0(-)^{\S}$ \\
\hline \multicolumn{5}{|c|}{ Metarhizium spp. } \\
\hline Ma01 & $7.85(P=0.031)$ & $7.54( \pm 4.3)$ & $13.8( \pm 1.56)$ & $23.1(-5.12)$ \\
\hline $\mathrm{Ma02}$ & $2.18(P=0.19)$ & $4.73( \pm 3.34)$ & $19.1( \pm 9.17)$ & $3.30(-5.61)$ \\
\hline Ma03 & $4.79(P=0.071)$ & $3.98( \pm 1.70)$ & $18.7( \pm 4.70)$ & $3.63(-5.28)$ \\
\hline Ma04 & $1.09(P=0.34)$ & $2.44( \pm 1.82)$ & $11.9( \pm 4.76)$ & $2.96(-5.94)$ \\
\hline Ma05 & $20.1(P=0.005)$ & $10.4( \pm 2.06)$ & $21.9( \pm 12.3)$ & $7.06(-55.3)$ \\
\hline Ma06 & $78.4(P<0.001)$ & $12.6( \pm 1.13)$ & $41.8( \pm 7.12)$ & $1.02(-61.3)$ \\
\hline Ma07 & $333.7(P<0.001)$ & $10.0( \pm 1.69)$ & $29.8( \pm 1.61)$ & $2.52(-44.3)$ \\
\hline Ma08 & $3.92(P=0.095)$ & $6.25( \pm 3.74)$ & $8.31( \pm 3.81)$ & $7.39(-44.3)$ \\
\hline Ma09 & $1.67(P=0.24)$ & $1.98( \pm 1.87)$ & $10.0( \pm 4.37)$ & $7.56(-35.1)$ \\
\hline \multicolumn{5}{|c|}{ Isaria farinosus } \\
\hline If01 & $2.16(P=0.19)$ & $2.41( \pm 1.66)$ & $9.96( \pm 3.44)$ & $52.9(-9.46)$ \\
\hline
\end{tabular}

Included are the main effects of treatment and their significance from the repeated measures ANOVA; the decline in feeding propensity averaged across the study period ( \pm 1 standard error around the mean decline in feeding propensity across replicates); the maximum feeding decline on any one day and the biting risk at day 14 ( \pm 1 standard error of the mean biting risk across replicates) around the mean mortality across the replicate cages). For both the latter measures the standard error around the mean. For further details see main text.

${ }^{a}$ Generated from repeated measures ANOVA (see main text). All assays were comparisons of one isolate and the control with each replicated four times.

${ }^{b}$ Calculated as the average proportion not feeding across the whole experiment until mortality had reached $80 \%$, or if this level was not been reached, then across the whole 14 days.

${ }^{c}$ Calculated as the product of the proportion of mosquitoes surviving at day 14 and the proportion responding to the feeding stimulant.

* Biting risk was zero because all mosquitoes had died in the fungal treatment.

$\S$ Biting risk was zero because none of the remaining fungal exposed mosquitoes responded to the feeding stimulant. 


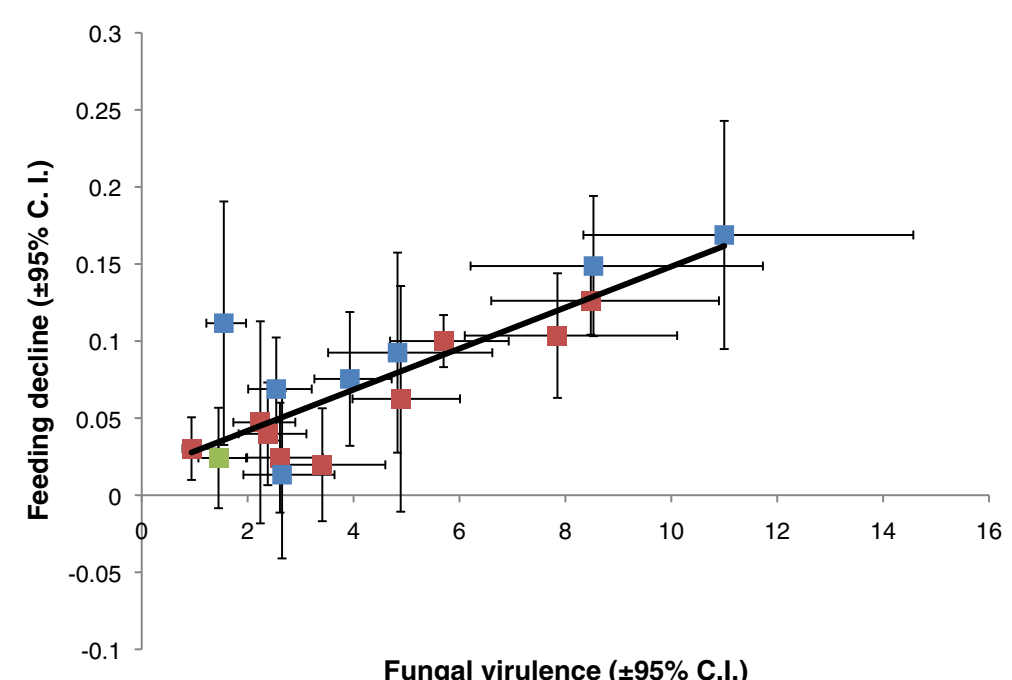

Fungal virulence $( \pm 95 \%$ C.I.)

Figure 3 The relationship between fungal virulence (the hazard ratio as in Table 2 and Figure $2 \mathrm{~A}$ ) and the reduction in feeding propensity (Table 3 and Figure 2 A). Fitted line shows a linear regression where Reduction in feeding propensity $=($ Hazard ratio $\times 0.015)+$ 0.013. Blue squares are B. bassiana isolates, red squares Metarhizium isolates and the green square an Isaria farinosus isolate.

it was practically zero). The Metarhizium isolates had a more mixed impact with biting risk greatly reduced relative to controls in five of the nine isolates tested but with reductions of between $35-61 \%$ only (Table 3 ). The single Isaria isolate caused only marginal declines in biting risk in line with its very modest virulence.

\section{Discussion}

The simple lab assay screen revealed that all fungal isolates examined had some effect on adult $A$. stephensi, reducing either survivorship, feeding propensity, or both. There was no obvious difference between fungal species in terms of virulence (the I. farinosus isolate had very low virulence but with a sample size of only one it is not possible to say whether this was a strain effect or species effect). In general the more virulent isolates also had the greatest impact on feeding, although for the combined metric of 'biting risk', the B. bassiana isolates tended to come out on top with several reducing biting risk to zero by day 14. Increased doses or more effective dose transfer would likely bring forward this impact to within one or two feeding cycles [18].

Several other studies have demonstrated reduced feeding propensity in mosquito vectors following fungal infection $[12,18,21,23]$. This is potentially a very important pre- or sub-lethal effect as there can be no transmission without feeding, even if the vectors are alive. The mechanisms involved in the anti-feeding effects are unclear. It has been suggested previously that feeding reductions are due to resource competition within the host and/or mechanical damage of host tissue as the fungal hyphae proliferate [58,59]. Fungal pathogens appear to go through a period of very low replication after infection followed by rapid increase in biomass just prior to host death $[39,60]$. Such growth patterns could explain the reductions in feeding observed here, especially for the virulent isolates. In addition, entomopathogenic fungi are known to produce their own enzymes for converting the host's stored sugars (e.g. trehalose) to glucose [61]. In phytophagous insects one of the feedback mechanisms implicated in decreasing motivation to feed involves a concentration gradient of glucose between the gut and haemolyph [62]. It is possible that fungal-induced changes in key nutrient gradients such as glucose could also play a role here [63]. Other (not mutually exclusive) mechanisms could include reduced olfactory sensitivity [24] or illness-induced anorexia in response to infection and immuno-stimulation [64]. Better understanding these mechanisms could help in screening or selecting isolates with stronger anti-feeding properties.

One interesting pattern revealed by this study is that isolates that induce more or less equivalent overall reductions in transmission potential can do so following very different daily mortality trajectories. Isolate $\mathrm{Bb} 01$ and $\mathrm{Bb} 04$, for example, both show zero biting risk at day 14 but $\mathrm{Bb} 01$ has an $\mathrm{LT}_{80}$ of 7.3 days while $\mathrm{Bb} 04$ has an $\mathrm{LT}_{80}$ of 11.3 days. Slower speed of kill potentially allows a higher proportion of lifetime reproductive output to be achieved and hence reduces selection pressure for resistance $[14,29]$. While no studies to date have shown resistance to insect fungal pathogens [65], evidence from other microbial agents used in insect control has shown resistance can evolve [66-68], and heritable genetic variation in susceptibility to B. bassiana has been demonstrated in Drosophila [69]. Given that the interest in 
alternative control tools is motivated by resistance against conventional insecticides, it could be valuable to evaluate potentially more 'evolution proof' isolates, such as Bb04, from the outset. An important note in this regard is that the number of isolates screened here represents a tiny sample of the available options. The USDA's fungus collection (Agricultural Research Service Collection of Entomopathogenic Fungi - ARSEF) holds an estimated 2,000+ B. bassiana and 2,500+ Metarhizium spp. isolates. Other national and international collections add to the list. With some very simple selection criteria (in this case the isolates were known to infect more than one insect taxa) it appears relatively straightforward to identify isolates that can infect mosquitoes. Under the current test conditions, all 17 isolates had some impact and a couple of the B. bassiana isolates appeared as good or better (in terms of virulence and anti feeding effects) than the B. bassiana isolate (IMI39150) that has been the focus of numerous recent mosquito studies. Given the political controversies surrounding GM organisms, it might be worthwhile exploring the rich fungal diversity within existing collections to better define natural variation in infection phenotypes before embarking on novel genetic engineering strategies to artificially generate desirable traits [70].

In conclusion, this study adds to growing evidence that fungal pathogens could contribute to disease vector control and offer a rich resource of phenotypes to explore. A basic screen such as this is a very long way from an operational product. In addition to desirable transmission blocking properties, any fungal product has to be amenable to mass production, store well after being produced and persist well after application, as well as meet stringent criteria for human and environmental safety $[4,31,71]$. While precedents for developing fungal biopesticides for use in agriculture in Africa and Asia exist [14], one current barrier to wider acceptance in public health is the restrictive WHOPES criteria used to evaluate products for inclusion in vector control portfolios. The approach of emphasizing only those products that kill vectors rapidly and can persist after application for six months or more currently excludes a number of novel interventions, not just fungi [29,72-77]. Given the looming resistance crisis in malaria these criteria require reassessment, particularly where products are to be used in integrated vector management strategies where their effectiveness depends on the 'sum of the parts' and not simply their stand alone contribution [78]. It is important that regulatory frameworks are amenable to innovative research and development and do not inadvertently create barriers to ultimate commercialization [78].

\section{Competing interests}

The authors declare that they have no competing interests.

\section{Authors' contributions}

SB, NEJ, AFR and MBT conceived and designed the experiments. SB and NEJ conducted the experiments. SB analysed the results. SB, MBT, AFR drafted the manuscript. All authors read and approved the final manuscript.

\section{Acknowledgements}

This research was part-funded by grants from Gates Grand Challenges Explorations (No. 53066), the National Institutes of Health (Al088094-01), the Innovative Vector Control Consortium and by the Research and Policy for Infectious Disease Dynamics (RAPIDD) program. This project was also funded, in part, under a grant with the Pennsylvania Department of Health using Tobacco Settlement Funds. The Department specifically disclaims responsibility for any analyses, interpretations or conclusions. All funders had no role in study design, data collection and analysis, decision to publish, or preparation of the manuscript.

\section{Author details}

${ }^{1}$ Center for Infectious Disease Dynamics, Department of Biology, Penn State University Mueller Laboratory, University Park, PA 16802, USA. ${ }^{2}$ Center for Infectious Disease Dynamics, Department of Entomology, Penn State University Merkle Lab, University Park, PA 16802, USA. ${ }^{3}$ Fogarty International Center, National Institutes of Health, Bethesda, MD 20892, USA.

Received: 21 August 2012 Accepted: 5 October 2012

Published: 5 November 2012

\section{References}

1. Zaim M, Guillet P: Alternative insecticides: an urgent need. Trends Parasitol 2002, 18:161-163.

2. Nauen R: Insecticide resistance in disease vectors of public health importance. Pest Manag Sci 2007, 63:628-633.

3. Dondorp AM, Yeung S, White L, Nguon C, Day NPJ, Socheat D, von Seidlein L: Artemisinin resistance: current status and scenarios for containment. Nat Rev Microbiol 2010, 8:272-280.

4. Dondorp AM, Fairhurst RM, Slutsker L, MacArthur JR, Breman JG, Guerin PJ, Wellems TE, Ringwald P, Newman RD, Plowe CV: The threat of artemisininresistant malaria. N Engl J Med 2011, 365:1073-1075.

5. Ranson H, N'Guessan R, Lines J, Moiroux N, Nkuni Z, Corbel V: Pyrethroid resistance in African anopheline mosquitoes: what are the implications for malaria control? Trends Parasitol 2011, 27:91-98.

6. Phyo AP, Nkhoma S, Stepniewska K, Ashley EA, Shalina N, McGready R, Ler Moo C, Al-Saai S, Dondorp AM, Lwin KM, Singhasivanon P, Day NPJ, White $\mathrm{NJ}$, Anderson TJC, Nosten F: Emergence of artemisinin-resistant malaria on the western border of Thailand: a longitudinal study. Lancet 2012, 379:1960-1966.

7. Chandra E, Hemingway J, Kleinschmidt I, Rehmna AM, Ramdeen V, Phiri FN, Coetzer S, Mthembu D, Shinondo CJ, Chizema-Kawesha E, Kamuliwo M, Mukonka V, Baboo KS, Coleman M: Insecticide resistance and the future of malaria control in Zambia. PLoS One 2011, 6:e24336.

8. N'Guessan R, Corbel V, Akogbeto M, Rowland M: Reduced efficacy of insecticide-treated nets and indoor residual spraying for malaria control in pyrethroid resistance area, Benin. Emerg Infect Dis 2007, 13:199-206.

9. Abilio AP, Kleinschmidt I, Rehman AM, Cuamba N, Ramdeen V, Mthembu DS, Coetzer S, Maharaj R, Wilding CS, Steven A, Coleman M, Hemingway J, Coleman M: The emergence of insecticide resistance in central Mozambique and potential threat to the successful indoor residual spraying malaria control programme. Malar J 2011, 10:110.

10. Hunt RH, Fuseini G, Knowles S, Stiles-Ocran J, Verster R, Kaiser ML, Choi KS, Koekemoer LL, Coetzee M: Insecticide resistance in malaria vector mosquitoes at four localities in Ghana. West Africa. Parasit Vectors 2011, 4:107.

11. Asidi S, N'Guessan R, Akogbeto M, Curtis C, Rowland M: Loss of household protection from use of insecticide-treated nets against pyrethroidresistant mosquitoes, Benin. Emerg Infect Dis 2012, 18:1101-1106.

12. Blanford S, Chan BHK, Jenkins N, Sim D, Turner RJ, Read AF, Thomas MB: Fungal pathogen reduces potential for malaria transmission. Science 2005, 308:1638-1641.

13. Scholte E-J, Ng'Habi K, Kihonda J, Takken W, Paiijmans K, Abdulla S, Killeen GF, Knols BGJ: An entomopathogenic fungus for control of adult African malaria mosquitoes. Science 2005, 308:1641-1643. 
14. Thomas MB, Read AF: Can fungal biopesticides control malaria? Nat Rev Microbiol 2007, 5:377-383.

15. Farenhorst M, Farina D, Scholte EJ, Takken W, Hunt RH, Coetzee M, Knols $\mathrm{BGJ}$ : African water storage pots for the delivery of the entomopathogenic fungus Metarhizium anisopliae to the malaria vectors Anopheles gambiae s.s. and Anopheles funestus. Am J Trop Med Hyg 2008, 78:910-916.

16. Mnyone LL, Lyimo IN, Lwetoijera DW, Mpingwa MW, Nchimbi N, Hancock PA, Russell TL, Kirby MJ, Takken W, Koendraadt CJM: Exploiting the behaviour of wild malaria vectors to achieve high infection with fungal biocontrol agents. Malar J 2012, 11:87.

17. Lwetoijera DW, Sumaye RD, Madumla EP, Kavishe DR, Mnyone LL, Russell TL, Okumu FO: An extra-domiciliary method of delivering entomopathogenic fungus, Metarhizium anisopliae IP 46 for controlling adult populations of the malaria vector. Anopheles arabiensis. Parasit Vectors 2010, 3:18.

18. Blanford S, Shi W, Riann C, Marden JH, Koekemoer LL, Brooke BD, Coetzee $M$, Read AF, Thomas MB: Lethal and Pre-lethal effects of a fungal biopesticide contribute to substantial and rapid vector control. PLoS One 2011, 6:e23591.

19. Paula AR, Carolino AT, Silva CP, Samuels RI: Susceptibility of adult females Aedes aegypti (Diptera: Culicidae) to the entomopathogenic fungus Metarhizium anisopliae is modified following blood feeding. Parasit Vectors 2011, 4:91.

20. Ansari MA, Pope EC, Carpenter S, Scholte E-J, Butt TM: Entomopathogenic fungi as a biological control for an important vector of livestock disease: the Culicoides biting midge. PLOS One 2011, 6:e16108.

21. Howard AFV, N'Guessan R, Koenraadt CJM, Asidi A, Farenhorst M, Akogbeto M, Thomas MB, Knols BGJ, Takken W: The entomopathogenic fungus Beauveria bassiana reduces instantaneous blood feeding in wild multiinsecticide-resistant Culex quinquefasciatus mosquitoes in Benin, West Africa. Parasit Vectors 2010, 3:87.

22. Scholte E-J, Takken W, Knols BGJ: Infection of adult Aedes aegypti and Ae. albopictus mosquitoes with the entomopathogenic fungus Metarhizium anisopliae. Acta Trop 2007, 102:151-158.

23. Scholte E-J, Takken W, Knols BGJ: Infection of the malaria mosquito Anopheles gambiae with the entomopathogenic fungus Metarhizium anisopliae reduces blood feeding and fecundity. J Invertebr Pathol 2005, 91:43-49.

24. George J, Blanford S, Domingue MJ, Thomas MB, Read AF, Baker TC: Reduction in host-finding behaviour in fungus-infected mosquitoes is correlated with reduction in olfactory receptor neuron responsiveness. Malar J 2011, 10:219.

25. Dolgin E: Evolution, Resisted. Scientist 2009, 23:44-57.

26. WHO: Guidelines for testing mosquito adulticides for indoor residual spraying and treatment of mosquito nets. Rome: World Health Organization; 2006. WHO/CDS/NTD/WHOPES/GCDPP/2006.3.

27. Hancock PA: Combining fungal biopesiticides and insecticide-treated bednets to enhance malaria control. PLoS Comput Biol 2009, 5:e10000525.

28. Hancock PA, Thomas MB, Godfray HCJ: An age-structured model to evaluate the potential of novel malaria-control interventions: a case study of fungal biopesticide sprays. Proc R Soc Lond B Bio 2009, 276:71-80.

29. Read AF, Lynch PA, Thomas MB: How to make evolution-proof insecticides for malaria control. PLOS Biol 2009, 7:e1000058.

30. Koella JC, Lynch PA, Thomas MB, Read AF: Towards evolution-proof malaria control with insectides. Evol Appl 2009, 2:469-480.

31. Darbro J, Graham RI, Kay BH, Ryan PA, Thomas MB: Evaluation of entomopathogenic fungi as potential biological control agents of the dengue mosquito, Aedes aegypti (Diptera: Culicidae). Biocontrol Sci Techn 2011, 21:1027-1047.

32. Mnyone LL, Kirby MJ, Lwetoijera DW, Mpinga MW, Knols BGJ, Takken W, Russell TL: Infection of the malaria mosquito, Anopheles gambiae, with two species of entomopathogenic fungi: effects of concentration, formulation, exposure time and persistence. Malar J 2009, 8:309.

33. Kikankie CK, Brooke BD, Knols BGJ, Koekemoer LL, Farenhorst M, Hunt RH, Thomas MB, Coetzee M: The infectivity of the entomopathogenic fungus Beauveria bassiana to insecticide-resistant and susceptible Anopheles arabiensis mosquitoes at two different temperatures. Malar J 2010, 9:71.
34. Leles RN, Sousa NA, Rocha LFN, Santos AH, Silva HHG, Luz C: Pathogenicity of some hypocrealean fungi to adult Aedes aegypti (Diptera: Culicidae). Parasitol Res 2010, 107:1271-1274.

35. de Paula AR, Brito ES, Pereira CR, Carrera MP, Samuels RI: Susceptibility of adult Aedes aegyti (Diptera Culicidae) to infection by Metarhizium anisopliae and Beauveria bassiana: prospects for Dengue vector control. Biocontr Sci Techn 2008, 18:1017-1025.

36. Farenhorst M, Mouatcho JC, Kikankie CK, Brooke BD, Hunt RC, Thomas MB, Koekemoer LL, Knols BGJ, Coetzee M: Fungal infection counters insecticide resistance in African malaria mosquitoes. Proc Natl Acad Sci USA 2009, 106:17443-17447.

37. Howard AFV, Koenraaddt CJM, Farenhorst M, Knols BGJ, Takken W: Pyrethroid resistance in Anopheles gambiae leads to increased susceptibility to the entomopathogenic fungi Metarhizium anisopliae and Beauveria bassiana. Malar J 2010, 9:168.

38. Howard AFV, N'Guessan R, Koenraadt C, Asidi A, Farnehorst M, Akogbeto M, Knols BGJ, Takken W: First report of the infection of insecticide-resistant malaria vector mosquitoes with an entomopathogenic fungus under field conditions. Malar J 2011, 10:24.

39. Bell AS, Blanford S, Jenkins N, Thomas MB, Read AF: Real-time quantitative PCR for analysis of candidate fungal biopesticides against malaria: Technique validation and first applications. J Invertebr Pathol 2009, 100:160-168.

40. Blanford S, Read AF, Thomas MB: Thermal behaviour of Anopheles stephensi in response to infection with malaria and fungal pathogens. Malar J 2009, 8:72.

41. Farenhorst M, Hilhorst A, Thomas MB, Knols BGJ: Development of fungal applications on netting substrates for malaria vector control. J Med Entomol 2011, 48:305-311.

42. Farenhorst M, Knols BGJ: A novel method for standardized application of fungal spore coatings for mosquito exposure bioassays. Malar J 2010, 9:27.

43. Mnyone LL, Koenraadt CJM, Lyimo IN, Mpingwa MW, Takken W, Russell TL: Anopheline and culicine mosquitoes are not repelled by surfaces treated with the entomopathogenic fungi Metarhizium anisopliae and Beauveria bassiana. Parasit Vectors 2010, 3:80.

44. Mnyone LL, Kirby MJ, Mpingwa MW, Letoijera DW, Knols BGJ, Takken W, Koenraadt CJM, Russell TL: Infection of Anopheles gambiae mosquitoes with entomopathogenic fungi: effect of host age and blood-feeding status. Parasitol Res 2011, 108:317-322.

45. Mnyone LL, Kirby MJ, Lweitojera DW, Mpingwa MW, Simfukwe ET, Knols BGJ, Takken W, Russell TL: Tools for delivering entomopathogenic fungi to malaria mosquitoes: effects of delivery surfaces on fungal efficacy and persistence. Malar J 2010, 9:246.

46. Mouatcho JC, Koekemoer LL, Coetzee M, Brooke BD: The effect of entomopathogenic fungi on female fecundity of the major malaria vector, Anopheles funestus. African Entomol 2011, 19:725-729.

47. Scholte E-J, Knols BGJ, Takken W: Autodissemination of the entomopathogenic fungus Metarhizium anisopliae amongst adults of the malaria vector Anopheles gambiae s.s. Malar J 2004, 3:45.

48. Scholte E-J, Njiru BN, Smallegange RC, Takken W, Knols BGJ: Infection of the malaria (Anopheles gambiae s.s.) and filariasis (Culex quinquefasciatus) vectors with the entomopathogenic fungus Metarhizium anisopliae. Malar J 2003, 2:29.

49. Achonduh OA, Tondje PR: First report of pathogenicity of Beauveria bassiana RBL1034 to the malaria vector Anopheles gambiae s.l. (Diptera; Culicidae) in Cameroon. African J Biotechnol 2008, 7:931-935.

50. Dong Y, Morton JC, Ramirez JL, Souza-Neto JA, Dimopoulos G: The entomopathogenic fungus Beauveria bassiana activate toll and JAK-STAT pathway-controlled effector genes and anti-dengue activity in Aedes aegypti. Ins Biochem Mol Biol 2012, 42:126-132.

51. Fang W, Vega-Rodriguez J, Ghosh AK, Jacos-Lorean M, Kang A, St Leger RJ: Development of transgenic fungi that kill human malaria parasites in mosquitoes. Science 2011, 331:1074-1077.

52. Garcia-Mungia AM, Garza-Hernandez JA, Rebollar-Tellez EA, Rodriquez-Perez MA, Reyes-Villanueva F: Transmission of Beauveria bassiana from male to female Aedes aegypti mosquitoes. Parasit Vectors 2011, 4:24.

53. Kannan SK, Murugan K, Kumar AN, Ramasubramanian N, Mathiyazhagan P: Adulticidal effect of fungal pathogen, Metarhizium anisopliae on malarial vector Anopheles stephensi (Diptera: Culicidae). African J Biotechnol 2008, 7:838-841. 
54. Mohanty SS, Raghavendra K, Rai U, Dash AP: Efficacy of female Culex quinquefasciatus with entomopathogenic fungus Fusarium pallidoroseum. Parasitol Res 2008, 103:171-174.

55. Mnyone LL, Russell TL, Lyimo IN, Lwetoijera DW, Kirby MJ, Luz C: First report of Metarhizium anisopliae IP 46 pathogenicity in adult Anopheles gambiae s.s. and An arabiensis (Diptera: Culicidae). Parasit Vectors 2009, 2:59.

56. Paula AR, Carolina AT, Paula CO, Samuels RI: The combination of the entomopathogenic fungus Metarhizium anisopliae with the insecticide Imidacloprid increases virulence against the dengue vector Aedes aegypti (Diptera: Culicidae). Parasit Vectors 2011, 4:8

57. Reyes-Villanueva F, Garza-Hernandez JA, Garcia-Munguia AM, Tamez-Guerra P, Howard AFV, Rodriguez-Perez MA: Dissemination of Metarhizium anisopliae of low and high virulence by mating behavior on Aedes aegypti. Parasit Vectors 2011, 4:171.

58. Hussain A, Tian M-Y, He Y-R, Ahmed S: Entomopathogenic fungi disturbed the larval growth and feeding performance of Ocinara varians (Lepidoptera: Bombycidae) larvae. Insect Sci 2009, 16:511-517

59. Tefera T, Pringle KL: Mortality and maize leaf consumption of Chilo partellus (Lepidoptera: Pyralidae) larvae treated with Beauveria bassiana and Metarhizium anisopliae. Int J Pest Manage 2004, 50:29-34.

60. Anderson RD, Bell AS, Blanford S, Paijmans KP, Thomas MB: Comparative growth kinetics and virulence of four different isolates of entomopathogenic fungi in the house fly (Musca domestica L.). J Invertebr Pathol 2011, 107:179-184.

61. Xia Y, Clarkson JM, Charnley AK: Trehalose-hydrolysing enzymes of Metarhizium anisopliae and their role in pathogenesis of the tobacco hornworm, Manduca sexta. J Invertebr Pathol 2002, 80:139-147.

62. Chapman RF: The Insects: Structure and Function. 4th edition. Cambridge: Cambridge University Press; 1998

63. Clements AN: The Biology of Mosquitoes: Sensory Reception and Behaviour Volume 2. Wallingford: CABI Publishing; 1999.

64. Adamo SA: Comparative psychoneuroimmunology; evidence from the insects. Behav Cognitive Neurosci 2006, 5:128-140.

65. Kraaijeveld AR, Godfray HCJ: Selection for resistance to a fungal pathogen in Drosophila melanogaster. Heredity 2008, 100:400-406.

66. Tabashnik BE: Evolution of resistance to Bacillus thuringiensis. Annu Rev Entomol 1994, 39:47-79.

67. Asser-Kaiser S, Fritsch E, Undorf-Spahn K, Kienzle J, Eberle KE, Gund NA, Reinecke A, Zebitz CPW, Heckel DG, Huber J, Jehle JA: Rapid emergence of baculovirus resistance in codling moth due to dominant, sex-linked inheritance. Science 2007, 317:1916-1918.

68. Abot AR, Moscardi F, Fuxa JR, SosaGomez DR, Richter AR: Development of resistance to Anticarsia gemmatalis from Brazil and the United States to a nuclear polyhedrosis virus under laboratory selection pressure. Biol Control 1996, 7:127-130.

69. Tinsley MC, Blanford S, Jiggins FM: Genetic variation in Drosophila melanogaster pathogen susceptibility. Parasitol 2006, 132:767-773.

70. Fang W, Vega R, Ghosh AK, Jacobs-Lorena M, Kang A, St Leger RJ: Development of transgenic fungi that kill human malaria parasites in mosquitoes. Science 2011, 331:1074-1077.

71. Thomas MB, Blanford S, Jenkins NE, Killeen GF, Knols BF, Read AF, Scholte E-J, Takken W: Benefits and risks in malaria control - response. Science 2005, 310:51-51.

72. Hughes GL, Koga R, Xue P, Fukatsu T, Rasgon JL: Wolbachia infections are virulent and inhibit the human malaria parasite Plasmodium falciparum in Anopheles gambiae. PLoS Pathog 2011, 7:2043-2043.

73. McMeniman CJ, Lane RV, Cass BN, Fong AWC, Sidhu M, Wang Y-F, O'Neill SL: Stable introduction of a life-shortening Wolbachia infection into the mosquito Aedes aegypti. Science 2009, 323:141-144.

74. Ren XX, Rasgon JL: Potential for the Anopheles gambiae densonucleosis virus to act as an "Evolution-Proof" biopesticide. J Virol 2010, 84:7726-7729.

75. Lorenz LM, Koella JC: The microsporidian parasite Vavraia culicis as a potential late life-acting control agent of malaria. Evol App/ 2011, 4:783-790.

76. Muller GC, Beier JC, Traore SF, Toure MB, Traore MM, Bah S, Doumbia S, Schlein Y: Field experiments of Anopheles gambiae attraction to local fruits/seedpods and flowering plants in Mali to optimize strategies for malaria vector control in Africa using attractive toxic bait methods. Malar J 2010, 9:262.
77. Beier JC, Muller GC, Gu WD, Arheart KL, Schlein Y: Attractive toxic bait (ATSB) methods decimate populations of Anopheles malaria vectors in arid environments regardless of the local availability of favoured sugarsource blossoms. Malar J 2012, 11:31.

78. Thomas MB, Godfray HCJ, Read AF, van den Berg H, Tabashnik BE, van Lenteren JC, Waage JK, Takken W: Lessons from agriculture for the sustainable management of malaria vectors. PLOS Med 2012, 9:e1001262.

doi:10.1186/1475-2875-11-365

Cite this article as: Blanford et al.: Evaluating the lethal and pre-lethal effects of a range of fungi against adult Anopheles stephensi mosquitoes. Malaria Journal 2012 11:365.

\section{Submit your next manuscript to BioMed Central and take full advantage of:}

- Convenient online submission

- Thorough peer review

- No space constraints or color figure charges

- Immediate publication on acceptance

- Inclusion in PubMed, CAS, Scopus and Google Scholar

- Research which is freely available for redistribution

Submit your manuscript at www.biomedcentral.com/submit
C Biomed Central 